\title{
Política de una fuga. Memoria y subjetivación política en la representación cinematográfica del poder desaparecedor en Argentina
}

Este artículo analiza tres películas sobre la representación de los Centros Clandestinos de Detención, Tortura y Exterminio en la última dictadura militar en Argentina (1976-1983): La noche de los lápices (1986) de Héctor Olivera, Garage Olimpo (1999) de Marco Bechis y Crónica de una fuga (2006) de Adrián Caetano. Nuestra lectura toma la idea de la fuga de la película de Caetano con el objetivo de desentrañar cómo estas representaciones cinematográficas, cada una en su momento, desbordaron las narrativas predominantes de la memoria histórica generando una suerte de desidentificación del espectador consigo mismo y con su rol en las políticas de la memoria. Para ello destacamos el análisis de ciertas secuencias específicas o imágenes políticas singulares que produjeron una torsión de la subjetivación y cuestionaron el fundamento político de esas narrativas. Desde esa perspectiva, la figura de la fuga se constituye en un locus de inteligibilidad para pensar cuáles son los límites del proceso contemporáneo de monumentalización de la memoria histórica.

En este artículo vamos a analizar tres películas sobre la representación de los Centros Clandestinos de Detención, Tortura y Exterminio (CCDTyE) en la última dictadura militar en Argentina (1976-1983): La noche de los lápices (1986) de Héctor Olivera, Garage Olimpo (1999) de Marco Bechis y Crónica de una fuga (2006) de Adrián Caetano. ${ }^{1}$ Cada filme refleja críticamente un período específico de la construcción de la memoria histórica en el país. Nuestra lectura toma la idea de la fuga de la película de Caetano con el objetivo de desentrañar cómo estas representaciones desbordaron las narrativas predominantes de la memoria generando una torsión en la subjetivación política. Desde esa perspectiva, presentamos un nuevo modo de mirar la memoria histórica a través de secuencias fílmicas que denominamos imágenes políticas singulares. Con ello nos referimos a aquellas imágenes cuya singularidad consiste en señalar el fundamento subjetivo donde reside nuestra percepción y conceptualización de la 
memoria histórica. Y a partir de allí nos permite re-elaborar, en el caso que abordamos, los límites de su proceso contemporáneo de monumentalización. Pero para llegar a ello, un rodeo histórico resulta necesario.

Partimos del estallido popular de 2001 que produjo una serie de rupturas con el modelo neoliberal de los años $90 .{ }^{2}$ El origen de este modelo puede encontrarse en la última dictadura cuando se lanzó una reforma financiera que cambió el patrón de acumulación de capital. ${ }^{3}$ Según León Rozitchner, las "jornadas del 2001" significaron una "ruptura con la cadena del terror" que había anudado economía y dictadura en el corazón de los sujetos sociales (39). Esta ruptura se expresó en el grito popular, que se vayan todos, que exigía la expulsión de la clase política que había llevado al país a la bancarrota, a la vez que abría el campo de la imaginación política "para crear valores de una sociabilidad alternativa a la dominante" (Colectivo Situaciones 86).

La tarea que nos proponemos aquí consiste en explorar cómo esta ruptura de la cadena del terror está íntimamente ligada a la lucha por la memoria histórica. Nos interesa pensar, específicamente, el modo en que las narrativas de la memoria se fueron resquebrajando hasta producir una torsión de la subjetivación política. Para ello, nos enfocamos en algunas representaciones cinematográficas del "poder desaparecedor y concentracionario" (Calveiro, Poder 13). En ese sentido, nos referimos a los CCDTyE que formaron parte de "la política desaparecedora de los años 70 (la cual) comprendió, junto a la desaparición de personas, el intento de desaparecer al mismo tiempo los crímenes y los responsables", de borrar la historia y las huellas del terror (Calveiro, Política 12).

RUPTURA Y/O TORSIÓN DE LA SUBJETIVACIÓN POLÍTICA EN EL CAMPO DE LA MEMORIA

Según Elizabeth Jelin, el campo de la memoria histórica está conformado por "procesos subjetivos" donde sus protagonistas "produ(cen) sentido" de sus experiencias del pasado, construyendo a cada una de "las memorias" como "un objeto de disputas, conflictos y luchas" (2). A su vez, Alejandra Oberti y Roberto Pittaluga consignan para las relaciones entre memoria e identidad el término "políticas de la memoria", mientras reservan "políticas en la memoria" para referirse a "la producción de subjetividades y de vínculos entre sujetos" que emerge en la práctica de la memoria (31).

En este artículo, denominamos subjetivación precisamente a las instancias de transformación individual y/o colectiva que emergen de esas prácticas poniendo en tensión las identidades generadas por las narrativas 
predominantes de la memoria. Al respecto, Jacques Rancière considera que "a process of subjetivation is a process of disidentification or declassification"; y al mismo tiempo afirma que "political subjectivation is the enactment of equality - or the handling of a wrong - by people who are together to the extent that they are [in] between" (67). Para Rancière, este "entre" o "in between" es señalado por un nombre que desborda las identidades: "It is the crossing of identities relying on the crossing of names: names that link the name of a group or class to the name of a no group or no class (i.e., the proletariat, the class that is not a class)"(67). Según nuestra interpretación, las imágenes políticas singulares producidas por las películas analizadas aquí cumplen un papel similar en el cine: su singularidad descansa en el hecho de que ellas nombran ese "entre", y al hacerlo, desbordan el marco explicativo de la memoria. Al mismo tiempo, son imágenes políticas en tanto penetran en el corazón de la subjetivación para señalar las desigualdades (de allí el "enactment of equality") que sostienen las relaciones entre dos identidades: el fundamento de su dominación.

En ese sentido, nos interesa destacar los procesos de desidentificación para indicar las instancias de transformación donde los sujetos se cuestionan a sí mismos en su fuero íntimo. Nos referimos a aquellas instancias donde la memoria y la subjetivación quedan desencajadas, desencontradas, y exigen una recomposición que vuelva inteligible esa misma desestabilización. Por lo tanto, cuando hablamos de una torsión en la subjetivación política en relación a la memoria, destacamos la des-identificación que cuestiona los vínculos entre identidades y sujetos en un momento histórico específico, y la trama política que se abre para dar cuenta de esas transformaciones.

En definitiva, se trata de vislumbrar las tensiones de la subjetivación entre la ruptura de la cadena del terror, tal como mencionaba Rozitchner, y las torsiones generadas alrededor de las películas analizadas. Efectivamente, la categorización de ruptura o torsión genera una tensión inherente al propio concepto de subjetivación en el sentido de identificar una gradación ( $i$ en qué momento una torsión se convierte en una ruptura?). Y más importante aún, nos permite pensar hasta qué punto realmente esta ruptura de la cadena del terror sostuvo su impacto subjetivo inicial, dado el restablecimiento del sistema político en 2003 y el rol del estado en la recomposición de una economía que no ha dejado de funcionar en torno a las leyes financieras del neoliberalismo. 
LAS NARRATIVAS DE LA MEMORIA Y EL PODER DESAPARECEDOR

En este marco, las tensiones de la subjetivación en el campo de la memoria histórica se organizan en relación a tres narrativas predominantes. Nos referimos a la "narrativa fundadora" (1983-1990); el "boom de la memoria" (1995-2003); y el proceso de monumentalización facilitado desde el estado (2004-2015). Si bien la periodización puede resultar esquemática, nos interesa señalar brevemente cómo se anudaron en ellas las representaciones del poder desaparecedor.

Primero, la narrativa fundadora impulsada por los organismos de derechos humanos generó alrededor de la figura del desaparecido el "mito de la inocencia". ${ }^{4}$ Este corte tajante entre dictadura y democracia que oponía victimarios y víctimas frente a una sociedad "ajena" al conflicto político, se vio interrumpido por la promulgación de las leyes de impunidad a mediados de los 80 y principios de los 90.5 Pero fundamentalmente manifestó un tipo de subjetivación política que, centralizada en la figura de la víctima, continuaba atada al encuadre dictatorial del cual buscaba des-identificarse. Segundo, durante el "boom de la memoria" la política desaparecedora se vinculó con el advenimiento del neoliberalismo en los noventa. ${ }^{6}$ Esto permitió que los procesos de memoria se conectaran con otras luchas contra la exclusión social, las cuales confluyeron en el estallido de 2001 y en la ruptura de la cadena del terror. Y tercero, en el periodo de monumentalización, el estado pasó a ser un articulador político central de los espacios de memoria en relación a los juicios a los militares, los monumentos públicos y la revalorización de la militancia como trama explicativa del poder desaparecedor. ${ }^{7}$ Esta nueva configuración que acercó el estado a las políticas de la memoria redujo la capacidad crítica de los organismos de promulgación de la memoria donde el horizonte político pensable se sustrajo al nudo de esa relación. Es en ese sentido que nos interesa elaborar cuáles son los límites de este anudamiento entre estado y memoria, el cual produjo una re-escritura de la historia reciente de la memoria en el país. ${ }^{8}$

Por último, cabe destacar que las películas analizadas aquí formaron parte de estas narrativas desde un punto de vista crítico y terminaron desbordando el marco histórico en el que se inscribían. Es decir: al mismo tiempo que generaron una torsión subjetiva, cada filme señaló los límites de las narrativas y la necesidad de pensar más allá de ellas. La película de Olivera interpeló a los espectadores a reconocerse en la figura del desaparecido abriendo la puerta para pensar la responsabilidad de la sociedad civil en la dictadura. Por su parte, Garage Olimpo iluminó el nudo subjetivo que sostenía la cadena del terror entre neoliberalismo y 
dictadura en los 9o. Y por último, el filme de Caetano señaló la necesidad de pensar la memoria histórica más allá de sus vínculos con el estado.

LA POTENCIA CREADORA DE LA FUGA

Nuestra apuesta consiste en indagar el significado múltiple de la fuga en Crónica de una fuga, para elaborarla como un lente contemporáneo que nos permite dilucidar las relaciones entre memoria y subjetivación. En efecto, como su nombre lo indica, el filme de Caetano relata el escape del CCDTyE "Mansión Seré" llevado a cabo por cuatro prisioneros quienes se fugaron desnudos luego de abrir una ventana con un tornillo en una noche de tormenta. ${ }^{9}$ Según Silvia Schwarzböck, el filme consigue plasmar "una historia real" donde la cámara se mimetiza con "la situación del que sufre", mientras exige "repensar el modelo de catarsis del terror contemporáneo, basado en la identificación del público con el verdugo, en lugar de con la víctima" (69). Por su parte, Gustavo Noriega esgrime que el filme narra la fuga "como si fuera un libro de Emilio Salgari" ("Fragmento" 97). Para el crítico, filmar la fuga como un thriller no significó una "despolitización", sino más bien "un gesto liberador" que le permitió distanciarse del "saber común de la época" (97).

A pesar de la importancia de estas consideraciones sobre el género cinematográfico, estas críticas no han destacado suficientemente el papel simbólico de la fuga más allá de la película. Fundamentalmente, Crónica de una fuga fue el primer filme ficcional sobre un escape de un CCDTyE. El hecho de que recién treinta años después del golpe de estado aparezca la posibilidad cinematográfica de mostrar una fuga llama fuertemente la atención. ¿Por qué no antes? Y además, se trata de la última película que cuenta en detalle la vida en los CCDTyE. ${ }^{10}$ Entonces habría que preguntarse qué estaba sucediendo en el terreno de la memoria para que emerja en ese momento la única ficción fílmica de un escape de los CCDTyE. Paradójicamente, la película de Caetano cierra el ciclo de la representación cinematográfica "ficcional" de los CCDTyE al mismo tiempo que los organismos de derechos humanos estaban "entrando" a la ex-ESMA (un CCDTyE real) para convertirlo eventualmente en el actual "Espacio memoria y derechos humanos"."

En una primera aproximación a la película, la fuga funciona a contrapelo de la historia, pues logra escaparse del imperativo de memoria que pendía sobre la representación cinematográfica de los CCDTyE: como si, a partir de "entrar" realmente a la exEsma, ya no se necesitara representar más esos antros del terror. ${ }^{12} \mathrm{Al}$ mismo tiempo, la fuga llama la atención sobre el rol del estado que habilitó esa misma "entrada": como si 
fuese necesario fugarse de la centralidad de ese vínculo entre estado y memoria.

Para nosotros, la fuga es el nombre que evoca la ruptura de la cadena del terror que hizo eclosión en 2001. Parafraseando a Horacio González, la fuga interpreta el que se vayan todos tomando de esa consigna su potencia "alegórica creadora" para preguntarse por "el origen de la política" de la memoria por fuera del estado (González, "Problemas" 52). Es decir, así como el grito popular simbolizó el estallido del 2001 estableciendo un nuevo punto de partida para poner en práctica otro modo de hacer política, la fuga generó un efecto de des-identificación cuyo horizonte político, alegórico, desbordó el marco de la monumentalización. Y de ese modo, el límite de la productividad crítica de la memoria habría quedado desde entonces, ominosa y simbólicamente estacionada en la ex ESMA.

INTROSPECTIVA DE LA FUGA：IRREPRESENTABILIDAD, INOCENCIA E IMÁGENES POLÍTICAS

El análisis concreto de las películas considera la tensión inherente de tener que presentar una ausencia (el desaparecido), a la vez que enfrenta el dilema de representar el funcionamiento del poder desaparecedor $y$ concentracionario. $^{13}$ Teniendo en cuenta esta condición de irrepresentabilidad, cada filme responde a las narrativas de la memoria antes mencionadas privilegiando el punto de vista de las "víctimas inocentes".

En efecto, La noche de los lápices retrata el secuestro y el cautiverio en los CCDTyE de un grupo de estudiantes del colegio secundario por haber reclamado por el boleto estudiantil en La Plata. ${ }^{14}$ Para Sandra Raggio, la película "es hija dilecta del juicio (a las juntas)" ya que se basa en el testimonio judicial de un sobreviviente, Pablo Díaz, y por lo tanto se inscribe en la narrativa fundadora (Raggio, "La noche" 58 ). ${ }^{15}$ Por su parte, Garage Olimpo cuenta la historia de María, una militante de clase media que es secuestrada, torturada y finalmente desaparecida en un CCDTyE en Buenos Aires. El filme contribuye al mito de la inocencia, ya que nada se sabe de su pasado militante salvo que enseña a leer y a escribir a los habitantes de una villa miseria. ${ }^{16}$ Asimismo Claudio, protagonista de Crónica de una fuga, es presentado como un joven "inocente" que juega al fútbol, estudia filosofía y atiende a algunas asambleas.

De ese modo, los tres filmes se identifican con la figura de la víctima inocente para describir al poder desaparecedor. Hasta Crónica de una fuga recurre a ello, a pesar de la legitimación de los relatos militantes propia de la monumentalización. Desde esa perspectiva, el vínculo intrínseco entre los tres filmes y los procesos de subjetivación no ha logrado torcer el nudo 
entre desaparición e inocencia. Inclusive la película Infancia clandestina (2011), si bien describe las vidas de los militantes, lo hace desde la mirada "inocente" de un niño.

Bajo esta condición de irrepresentabilidad de los desaparecidos y la constante de la inocencia, nuestra lectura de cada película procura ver cómo funciona la figura de la fuga en relación a tres variables: las tensiones espaciales, el uso de las miradas y el impacto de imágenes políticas singulares, las cuales producen una des-identificación entre el espectador y las narrativas predominantes sobre el poder desaparecedor. La fuga opera no sólo como un pensamiento inevitable dentro de los CCDTyE todo prisionero quiere escaparse-, sino también funciona, figurativamente, como la necesidad política de des-identificarse del estado (o romper con él) para restablecer las conexiones entre memoria y subjetivación. En ese sentido, la fuga evoca "la ruptura" para producir una torsión de la subjetivación y nos permite, a partir de allí, revisitar otras imágenes políticas singulares que llevaron a cabo un cuestionamiento similar de las narrativas de la memoria.

LA NOCHE DE LOS LÁPICES: AMOR, INTERPELACIÓN Y ESTRUCTURA BINARIA

La noche de los lápices fue la primera película en mostrar escenas explícitas de tortura y encierro sufridas por prisioneros en un CCDTyE. ${ }^{17}$ El filme le dio cuerpo a la figura del desaparecido siguiendo la mirada del último testigo verosímil que los vio con vida, a través de "una historia de amor (cuya trama) opera(ba) como metáfora de la política de los setenta" (Raggio, "La noche" 65).

La película cuenta la historia de un grupo de adolescentes donde la lucha por el boleto estudiantil aparece entrelazada con la "historia de amor" entre Pablo Díaz y Claudia Falcone (65). ${ }^{18}$ Este idilio inicial se corta con el secuestro de los estudiantes a manos de grupos de tareas que una noche ingresan a sus casas para llevarlos detenidos. ${ }^{19}$ A partir de allí, el filme transcurre en distintos CCDTyE, alternándose con un montaje de escenas de la lucha de los familiares que buscan a sus seres queridos sin tener respuesta de la sociedad (66). Juan Carlos Kusnetzoff ha denominado esta falta de respuesta social con el nombre de "percepticidio" o "muerte de la percepción" basado en los mecanismos psicológicos de la renegación o la desmentida (108). Se trata de una doble negación donde parte de la sociedad no sólo niega la desaparición forzada de personas, sino que a pesar de la evidencia, se comporta "como si la ausencia no existiera" (108).

De ese modo, la película despliega un esquema binario donde divide las secuencias antes y después de los CCDTyE, para luego realizar un corte 
entre el adentro y el afuera de los mismos. Una vez allí, la cámara pasa por dos centros de detención distintos: en uno, se muestra la tortura que sufrió Pablo y la vida de-subjetivante. ${ }^{20} \mathrm{Y}$ en el otro, el protagonista se reencuentra con sus amigos del secundario, lo cual habilita cierta recomposición subjetiva dentro de la vida concentracionaria. ${ }^{21}$ Para Raggio, este esquema espacial binario busca generar una "identificación" de los espectadores con la mirada de "la cámara" y "los personajes", a fin de instaurar la sensación de que, inocencia mediante, cualquiera pudo haber sido víctima de la dictadura (71-72). De ese modo, el filme busca romper con cierta "politics of looking" que, de acuerdo con Diana Taylor, "forced people to look away - a gesture that undid their sense of personal and communal cohesion even as it seemed to bracket them from their volatile surroundings" (122).

Desde nuestra lectura, quisiéramos destacar cómo este efecto subjetivo se logra a través del símbolo de la venda. En efecto, el afiche publicitario del filme muestra la cara de Pablo Díaz con una venda en los ojos y a los otros estudiantes "desaparecidos" sin venda, mirando en distintas direcciones, salvo Claudia que mira directamente al espectador. De ese modo, al colocar la venda en el sobreviviente, los desaparecidos adquieren una capacidad de ver y de interpelar a los espectadores: es la venda que parte de la sociedad "utilizó" durante todos esos años para no ver lo que sucedía a su alrededor. Y por lo tanto, esta interpelación puede pensarse como una invitación a sacarse la venda que tuerce las coordenadas de la subjetivación política: a partir de entonces no puede pensarse lo político sin ejercer la memoria.

Este gesto puede leerse como una fuga de la narrativa dictatorial que justificaba la guerra sucia y el percepticidio a través de la instalación de un imperativo de la memoria concreto: la necesidad de ver qué pasó en los CCDTyE. En la última escena, un guardia le saca la venda a Pablo y le dice: "Mirame, yo te traté bien ... como un ser humano, ¿no?" (Olivera 1:29). Hete aquí la desmentida como mecanismo social: el militar niega la desaparición frente al "desaparecido", y entonces Pablo, que ha sido torturado, ahora "aparece" como ser humano. Acto seguido, el guardia le "permite" despedirse de Claudia en su celda. ${ }^{22}$ En ese diálogo, Pablo intenta darle esperanza, hasta que Claudia le dice que la violaron, que ella ya no puede ser la misma. "Nosotros ya estamos muertos" - concluye. Y cuando su compañero se va, le grita: “Pablo, no te olvides de mí!” (1:31).

Si hay un lugar para pensar la figura de la fuga en el filme, reside en esta secuencia que termina por sacarle la venda al espectador. Sin embargo, la alegoría creadora del imperativo de la memoria tiene sus limitaciones pues son los militares los que deciden sacarles la venda: tanto 
a Pablo como, simbólicamente, al espectador. Y de ese modo, la inocencia esperanzadora del protagonista se redobla por aquella inocencia encubridora de la sociedad, para confluir en una misma figura de la víctima inocente. Del otro lado queda Claudia, muerta antes de desaparecer, clamando por la memoria.

De ese modo, La noche de los lápices busca fugarse de la narrativa dictatorial, pero reproduce los mecanismos binarios del poder desaparecedor- victimario/víctima, adentro/afuera, dictadura/democracia - pues al presentar al desaparecido como una víctima inocente, desaparece la trayectoria militante de los personajes. Y a la vez, a pesar de su alcance masivo, se "ocluye que la sociedad misma se reconozca en la historia por fuera de esa dicotomía" (Raggio, "La noche" 72). 0 en otras palabras, la denuncia de la muerte de la percepción opera aun bajo el resabio de la desmentida.

Sin embargo, el filme abrió un nuevo escenario de la memoria más allá de sus contradicciones e imprecisiones históricas, que generaron no pocas controversias. ${ }^{23}$ Inclusive Pablo Díaz se convirtió en un militante del filme y realizaba charlas públicas luego de su proyección (Lorenz 6o). ${ }^{24}$ La difusión nacional e internacional de la película ha superado a cualquier otra sobre la representación de la dictadura, y tal como dice Raggio, ha producido un efecto de verdad en la sociedad "hasta el punto que no logra distinguirse 'el hecho' que se recuerda de su relato cinematográfico" (Raggio, "La noche" 73). ${ }^{25}$

Raggio cuenta que en una de las marchas conmemorativas de "La noche de los lápices", a la que acudió Pablo Díaz, su foto "estaba junto a la de los seis estudiantes desaparecidos" (73). Lo "singular" de la imagen es que en este tipo de marchas, las fotos están reservadas para representar a los desaparecidos. En esa marcha, la figura simbólica de Pablo Díaz desbordó su propia representación en la pantalla, y así pasó a funcionar como una imagen política cuya acción militante cuestionaba la representación de los desaparecidos como inocentes propuesta por el filme. Esa imagen política que surgía en la marcha se había fugado de la película para ubicarse en la frontera entre el sobreviviente y el desaparecido, entre el presente y el pasado, entre la pantalla y la realidad. Y desde allí se desprendía un instante de fuga, ominoso y político a la vez: como si en esas pancartas le hubiesen quitado la venda que Pablo tenía en el afiche publicitario del filme, y por un instante, su presencia real en la marcha se viese superada por esa estela que encarnaba su figura. 
GARAGE OLIMPO: LA CADENA DEL TERROR Y LA VENDA

Trece años más tarde, y con un impacto social mucho menor, se proyecta en Argentina Garage Olimpo. ${ }^{26}$ El filme elabora la cadena del terror entre neoliberalismo y democracia mediante el señalamiento de ambivalencias que desarman la imagen binaria (el corte entre dictadura y democracia) que proponía $L a$ noche de los lápices. ${ }^{27}$ Esto fue recibido muy positivamente por la crítica local, aunque estructuralmente no se distancie tanto de su predecesora. ${ }^{28}$ En efecto, la película utiliza testimonios de sobrevivientes, despliega las tensiones espaciales en el CCDTyE y recurre desde su afiche publicitario al uso simbólico de la venda. ${ }^{29}$ Pero sobre todo, su hilo narrativo es la "historia de amor" entre María y un torturador, Félix.

Sin embargo, a diferencia de su predecesora, esta historia de amor está atravesada por una relación de poder desigual donde Félix está a cargo de María dentro del CCDTyE: él la tortura, pero la "protege" del asedio de otros guardias. Además, le permite sacarse la venda en su presencia y tomar mate con ella en la celda. Por su parte, María acepta este "cuidado" pero sus sentimientos hacia Félix se mueven en una zona ambigua.

Según Valeria Manzano, "el filme construye figuraciones en torno al espacio" mediante la combinación de imágenes aéreas de la ciudad con imágenes subterráneas del CCDTyE, las cuales transmiten una sensación claustrofóbica como si ambos fueran "un espacio único" (158). A su vez, Horacio González destaca la escena del "transeúnte ... (que) pasa cansinamente frente a (la) fachada (del CCDTyE). La vida afuera no sólo es "normal", sino que se desarrolla ahí al lado, luego de traspasada la inmediata frontera" (González, "Procedimiento" 167). Estas "tensiones espaciales" establecen un límite frágil entre el adentro y el afuera que si bien resulta imposible de franquear, a la vez, abre la posibilidad de la fuga.

En el filme, la protagonista aprovecha un descuido de los torturadores, ve la puerta del garaje abierta y se lanza en una carrera para atravesarla; y si bien consigue cruzarla, inmediatamente es atrapada por un guardia. Igualmente, cuando Félix "sale a pasear" con María por la ciudad, ella se adelanta unos pasos en medio del tumulto de gente y comienza a correr, pero el torturador le da alcance. Este fracaso de los intentos de fuga demuestra la distancia tenue entre el adentro y el afuera, entre la normalidad y el horror, imperceptible para un "transeúnte" cuya indiferencia es también una representación de las características propias de la sociabilidad neoliberal de los 9o. Y al mismo tiempo, deja abierta una rendija por donde el escape del CCDTyE era al menos imaginable para los prisioneros; y por lo tanto, permite vislumbrar, en su alegoría con la sociabilidad de los noventa, que la cadena del terror ya se estaba resquebrajando. 
Susana Draper sostiene que "the film creates a zone of ambiguity between impotence and escape and dramatizes the problem of disassociation between the gaze and narrative in the character of María" (193). En efecto, apenas entra al CCDTyE, uno de los torturadores le pone una venda a María mientras le dice: "Acá no vas a ver nada, este es el mundo de los sonidos ... Acá nosotros somos Dios, porque decidimos quién muere y quién vive" (Becchi o.18). Este "rito de pasaje" introduce al prisionero al CCDTyE como un ser cuya percepción visual ha muerto y dependen del dios militar que, como dice Margarite Feitlowitz, pone a funcionar "an extensive argot ...through language. Through the reality created by and deflected in words" (57).

Para Manzano, esa pérdida de la capacidad de ver dispara "la desubjetivación de los detenidos" (Manzano 160). Y más adelante en el filme, un compañero le dice a María cómo fingir para resistir, pero le advierte que no lo haga "con los ojos, porque ellos siempre te buscan la mirada" (Becchi o.45). Según Manzano, la estrategia consiste en "construirse una venda imaginaria ... resistir mediante una 'posición de venda"' (162). Y en ese sentido, la lucha contra la muerte de la percepción comienza en el CCDTyE mismo. Esta imagen se refleja en los espectadores quienes, durante la dictadura (pero también en los noventa) "perdieron su capacidad de mirar ... (y) diluyeron su subjetividad" (164)..$^{30}$

Este enfoque en la mirada se vio reforzado por la masiva pegatina de afiches que mostraban la publicidad del filme con el título y la cara de María vendada, la cual precedió a su proyección comercial en Buenos Aires. Desde esa perspectiva, el filme no proponía sacarse la venda sino que exigía preguntarse cómo esa posición de venda era el resultado del percepticidio que había calado hondo en la subjetividad de los noventa.

De hecho María, antes de ser secuestrada, se prueba la ropa que Félix robó de algún operativo, y por lo tanto, "actúa" (sin saberlo) desde esa posición de venda, ignorando la cadena del terror y reforzando la misma (Manzano 173). Por su parte Félix ejerce la tortura al mismo tiempo que juega ping pong o marca tarjeta en el CCDTyE. Este es el efecto del mecanismo de desmentida como sustento de la muerte de la percepción, pues Felix, a diferencia de María, sabe qué hace, y lo hace negando el efecto de horror que produce: como si estuviera haciendo una tarea cotidiana normalizada.

Los efectos de-subjetivizantes de este tipo de escenas ominosas, ambiguas y claustrofóbicas allanaron el camino para la escena "espeluznante" del final. Allí, un avión militar Hércules C-13o vuela sobre el Río de la Plata con el objetivo de arrojar seres humanos vivos al agua, mientras de fondo suena "Aurora", la canción a la bandera nacional. ${ }^{31}$ 
Entonces la posición de venda se desvanece: la conexión de la imagen del avión con ese "himno" patriótico que se cantaba en las escuelas "todas las mañanas al izar la bandera ... en Argentina produjo un cortocircuito cerebral" (Bechis 1). ${ }^{32}$ Las dos vías estatales de nacionalización de la "identidad argentina" se juntaron en esta imagen política singular: la escuela y las FFAA, las cuales habían sido introyectadas como base de la formación subjetiva de los argentinos desde fines del siglo $19 .{ }^{33}$

Esa des-carga de los detenidos desaparecidos desde el avión, coincide con la des-carga del peso de una herencia histórica. Entonces, el filme rompe la ajenidad del espectador "inocente", generando una torsión de la subjetivación política que lo deja sin coordenadas para el escape de ese espacio único. Leída en retrospectiva: al fracasar la fuga, la alegoría creadora de la escena consiste en despejar la posición de venda para devolverle la mirada al espectador: una mirada ominosa, terrorífica y, en última instancia, "enceguecida", ya que el origen político del poder desaparecedor se retrotrae a la fundación del estado-nación. La escena introyecta en la subjetivación una posición de mirar "ciega", en el sentido de que el espectador se queda sin referentes históricos "nacionales". Para nosotros, esta potencia ciega va a plasmarse en la ebullición de proyectos políticos y sociales pos-2001 los cuales, ante la ausencia del estado, tuvieron que reconfigurar una sociabilidad alternativa para la resolución de los conflictos cotidianos.

CRÓNICA DE UNA FUGA: ...COMO CUANDO ESTÁBAMOS AFUERA

Crónica de una fuga llega a las pantallas del cine argentino cinco años después de aquel estallido social, en medio de la expansión monumental de la memoria. A pesar de ello, la proyección del filme no tuvo ni la popularidad de La noche de los lápices, ni la elogiosa crítica de Garage Olimpo. ${ }^{34}$ Esto se debió en parte a que la película estaba encuadrada en la expansión industrial del nuevo cine argentino del cual el director es uno de sus "íconos" (Schwarzböck 7-8). ${ }^{35}$ Reflejaba, además, la sensación de agotamiento que despertaba un nuevo filme sobre la temática.

Luego de la breve filmación del secuestro de Claudio, la película se desenvuelve enteramente dentro de la Mansión Seré (salvo una escena) hasta que se produce la fuga, y la cámara sale definitivamente del CCDTyE. Así, el filme genera una división tajante del adentro y del afuera que permite desplegar las tensiones espaciales. ${ }^{36}$ Pero, a diferencia de las otras, esta película no cuenta "una historia de amor" sino que se enfoca en la relación de "convivencia" entre torturadores y prisioneros desde el punto de vista de cuatro presos que comparten una celda: Guille (Guillermo Fernández), Gallego, Vasco y Claudio. ${ }^{37}$ 
Según Schwarzböck, "la cámara de Crónica de una fuga enfoca y desenfoca figuras y objetos" desde el punto de vista de los prisioneros "en un esfuerzo deliberado por ponerse espacialmente en su lugar" (58). Desde esa perspectiva, los detenidos tienen que "subirse y bajarse la venda" de acuerdo a la situación, como cuando la cámara asume la posición de Claudio que se está despertando y tiene que inclinar la cabeza para enfocar su vista. Incluso en el afiche promocional del filme la venda no aparece. Así, más que como un símbolo, la venda funciona como un obstáculo práctico dentro de los juegos de la mirada propios del CCDTyE.

En una escena, el torturador Lucas pone un pedazo de espejo frente al prisionero: "Miráte Gallego, ¿te reconocés? Afuera tampoco te reconocen". Esta de-subjetivación que aplasta la mirada y la imagen, la percibe/descubre Claudio antes de la fuga: "Ya estamos muertos, Gallego. Estamos desapareciendo". En su reverso, la reivindicación de la mirada se realiza también en ese límite de la muerte, como cuando en un simulacro de fusilamiento, Guille pide que le quiten la venda para ver quiénes son sus asesinos.

En contraposición a estos juegos de la mirada y la espacialidad, la escena clave sucede cuando Guille va a entregar una casa con el grupo de tareas. Allí la cámara sale del CCDTyE y filma a Guille tocando el timbre en una casa "típica" de clase media urbana. Del otro lado lo recibe el personaje del juez que le da una sentencia de muerte por darle datos falsos. Con ello se produce una doble inversión: en primer lugar, el actor que encarna a este juez es precisamente Guillermo Fernández, quien ahora interpreta a su verdugo enfrentándose a sí mismo.$^{38} \mathrm{Y}$ en segundo lugar, la escena presenta a un juez que, en una situación ilegal, firma una sentencia de muerte en una casa secuestrada por el estado militar.

En la escena siguiente, Lucas los ata desnudos a unas camas de fierros y les pasa un cepillo con agua sucia por el cuerpo. Esta tortura, en la lógica de Lucas, es para "limpiarlos" por el pecado de haber dado información falsa. ${ }^{39}$ En el delirio de la misma, un tornillo se desprende de una cama, el cual será utilizado para abrir la ventana que los conduce a la fuga. Pero, más importante aún, luego de esta tortura Guille le comunica a sus compañeros de celda su determinación a escaparse: "Hay que pensar como cuando estábamos afuera. Es más fácil de lo que parece".

RETROSPECTIVA DE LA CADENA DEL TERROR: LA RUPTURA Y LA FUGA En esta frase está contenido el quiebre de la subjetivación que propone la película y que atraviesa el corazón de la memoria histórica. Hacia adentro del CCDTyE significa que el encierro no es tan eficaz si podemos imaginar ese afuera: es más fácil de lo que parece. $\mathrm{Y}$ al mismo tiempo, pensar como 
cuando estábamos afuera refiere tanto al exterior del CCDTyE durante la dictadura, como al exterior de la monumentalización de la memoria contemporánea. Así, del mismo modo que el que se vayan todos desplazó a los referentes de la clase política y funcionó como una alegoría creadora para imaginar un tipo alternativo de sociabilidad durante la crisis de 2001, la alegoría creadora de la fuga procura señalar la necesidad de pensar más allá de la centralidad del vínculo entre estado y memoria.

La imagen política singular de los cuatro protagonistas escapando desnudos del CCDTyE reflejaba el resultado de la producción de sujetos desamparados llevada a cabo por el poder desaparecedor. Al mismo tiempo, el desborde de esa singularidad generó una torsión en la subjetivación política al transformar esa debilidad extrema en un momento de agencia: la fuga. Parafraseando a Noriega, ese thriller de la desnudez constituyó una ruptura con la memoria en términos del género y la falta de referencia histórica. Pero, más significativo aún, en esa imagensecuencia resonaba "la dignidad de la revuelta de millones de excluidos, reducidos al desamparo y a condiciones mínimas de supervivencia" que a partir del estallido de 2001 pudieron visualizar un nuevo horizonte político (Amado 212).

En síntesis, este nuevo modo de mirar la memoria a través de imágenes políticas singulares que criticaron las narrativas predominantes sobre el poder desaparecedor y los CCDTyE nos permitió situar la fuga como un lente histórico y político. Esta figura se inserta en las tensiones de la subjetivación política que se dirimen entre la ruptura de la cadena del terror y una torsión subjetiva para plasmarse en los filmes analizados como cuestionamientos de esas mismas narrativas. En La noche de los lápices, la interpelación del desaparecido instaló el imperativo de la memoria para pensar lo político. En Garage Olimpo, la descarga de los cuerpos en el río desde el avión militar conectó el poder desaparecedor con el fundamento del estado-nación mientras invitaba a re-pensar el fundamento de lo político más allá de esa historia nacional. Por último, Crónica de una fuga presentó el thriller de la desnudez donde la fuga reinterpretaba el que se vayan todos manteniendo su estado de alegoría, como decía González, para anclar un pensamiento de lo político más allá del vínculo entre estado y memoria histórica. Es este gesto final, que denominamos política de una fuga, el que nos exige pensar como si estuviésemos afuera de la monumentalización de la memoria.

Elon University 
NOTAS

$1 \quad$ Los CCDTyE eran sitios clandestinos manejados por las fuerzas represivas del estado donde se torturaba, mataba y desaparecía a detenidos por razones políticas. El informe Nunca Más (1984) calcula que hubo 340 en todo el país (CONADEP 59). A su vez, organismos de derechos humanos han estimado que hubo alrededor de 30 mil desaparecidos.

2 La revuelta social hizo epicentro en la ciudad de Buenos Aires y terminó por destituir 5 presidentes en menos de 20 días. Ver Colectivo Situaciones.

3 La Reforma Financiera de 1977 funcionó como el "puntapié (inicial) para la emergencia de un modo de acumulación ... neoliberal” que reemplazaría al patrón de acumulación agroindustrial (Manzano 171).

$4 \quad$ Los pilares de la narrativa fundadora fueron el Nunca Más (1984) y el Juicio a las Juntas (1985), en el cual se condenó a prisión a los jefes máximos de la dictadura. Esta narrativa sostenía la "teoría de los dos demonios", según la cual "durante la década del 70 la Argentina fue convulsionada por un terror que provenía tanto de la extrema derecha como de la extrema izquierda" equiparando erróneamente ambas formas de violencia (CONADEP 11).

5 Las "leyes de impunidad" fueron: la Ley de Punto Final (1986) que ponía un plazo para la presentación de demandas judiciales; la Ley de Obediencia Debida (1987), que exculpaba a todo subordinado militar por actuar bajo las órdenes de un superior; y los Indultos Presidenciales (1989 y 1990) que dejaron libres a los condenados en el Juicio a las Juntas. Ver Bernazza.

$6 \quad$ Utilizado por Daniel Lvovich y Jaquelina Bisquert, el término "boom de la memoria" refiere a la ebullición de relatos tales como: declaraciones de militares, testimonios militantes, discursos de nuevas generaciones y trabajos de investigación sobre la memoria (59).

$7 \quad$ La derogación de las leyes de impunidad en 2003, la reapertura de los juicios a los militares y "la creación de un Espacio para la Memoria" en la ex-ESMA reestructuró la relación entre organismos de derechos humanos y el estado, aun cuando se continuó con el patrón de acumulación financiero (Lvovich y Bisquert 81).

8 El hito de esta re-escritura es la publicación en 2006 de una nueva edición del Nunca Más incluyendo un nuevo prólogo que afirma su distancia con el prólogo de 1984, el cual sostenía la teoría de los dos demonios como explicación de la violencia política en los años 7o. Sin embargo, el nuevo texto no discute el anterior, sino que lo descarta asumiendo que ya ha sido refutado (para un análisis del mismo ver Vezzetti). De modo similar, el kirchnerismo se presenta a sí mismo como salvador de la crisis de 2001 sin reconocer allí la multiplicidad de nuevos protagonismos sociales (ver Colectivo Situaciones). 
9 Crónica de una fuga se construye en función de la novela testimonial Pase Libre: la fuga de la Mansión Seré de Claudio Tamburrini (2002) quien fue uno de los protagonistas del escape del 31 de marzo de 1978.

1o Desde 2006, no conozco ningún filme de ficción enfocado en el funcionamiento de los CCDTyE en Argentina.

" Actualmente la "ex-ESMA" se encuentra institucionalmente articulada por el estado nacional, el gobierno de la ciudad de Buenos Aires y organismos de derechos humanos (ver http://www.espaciomemoria.ar/). Sin embargo, entre el Convenio firmado el 24 de marzo de 2004 y la desocupación final de las Fuerzas Armadas el 20 de noviembre de 2007 se generaron distintos debates sobre qué hacer con el predio (ver Vezzetti 203-258).

12 Una vez consumada la fuga en 1977, la Mansión Seré fue demolida por los militares para desaparecer las huellas de la ignominia. Además, hay que señalar que en septiembre de 2006, Julio López, un testigo que declaró en un juicio contra los militares, desapareció al día siguiente y aún hoy no ha vuelto a aparecer.

13 La condición de irrepresentabilidad aparece como límite de los "relato(s) de la represión y el sufrimiento" de los sobrevivientes de los CCDTyE quienes no han llegado a experimentar lo mismo que los desaparecidos (Jelin y Longoni $\mathrm{XVI)}$. Esto es distinto de la imposibilidad de representar, ya que como sostiene Pierre Vidal Naquet, si "el genocidio (nazi) fue pensado e imaginado por sus responsables ... ello demuestra que es posible pensarlo e imaginarlo" para representarlo (en Crenzel 13).

14 La manifestación por el boleto escolar se llevó a cabo el 5 de septiembre de 1975, mientras que los secuestros se realizaron entre el 15 y 16 de setiembre de 1976 (Raggio, "La construcción" 154). En realidad, se trató de "un operativo contra un grupo montonero" que formaba parte de la Unión de Estudiantes Secundarios (salvo Pablo Díaz que pertenecía a la Coordinadora de Estudiantes Secundarios), entre los cuales había algunos que tenían armas guardadas en sus casas (Vezzetti 111).

15 Pablo Díaz estuvo encerrado en los CCDTyE de Arana y Pozos de Quilmes y Banfield hasta febrero de 1977, para luego pasar a una cárcel común hasta 1980 cuando fue liberado.

16 Acaso la película procura salvar esa distancia con el personaje de Ana, quien pone una bomba en la casa de un policía, que resulta ser el jefe del CCDTyE donde estaba detenida María. Este personaje está basado en "Ana María González, militante montonera que en junio de 1976 puso una bomba debajo de la cama del Jefe de la Policía Federal” y luego sería desaparecida por la máquina de terror estatal (Manzano 173). Sin embargo, esta referencia a la violencia política de izquierda resulta controvertida, ya que en la lógica del filme, todos los detenidos de ese CCDTyE son desaparecidos en revancha por 
la explosión de la bomba. Manzano ha vislumbrado aquí una posible reproducción de "la teoría de los dos demonios" donde la "víctima inocente" es asesinada dentro del CCDTyE como resultado de dos violencias ajenas.

${ }^{17}$ Las fotos del Nunca Más retratan los CCDTyE luego de haber sido desmantelados por los militares.

I8 La película también representa la historia de amor entre María Clara Ciocchini y Horacio Húngaro.

19 También aparecen representados en el filme Francisco López Montaner, Claudio Acha y Daniel Rancero.

20 El uso de la picana eléctrica, el parto de una chica detenida y el simulacro de fusilamiento son los momentos de mayor tensión disruptiva del filme.

2I En el “(Pozo de Banfield) se distiende la tensión dramática” y se retoma la historia de amor: los detenidos hacen chistes, se ríen, conversan y cantan a coro entre las celdas (Raggio, "La noche" 7I).

22 La película no explica el porqué de su liberación, e incluso el propio Pablo Díaz cree que algún pariente lejano conectado con los militares lo ayudó, pero nunca pudo saberlo porque no se comunica con ellos.

23 Según la Asamblea Permanente por los Derechos Humanos "la exhibición de la película produ(cía) tal pánico entre los estudiantes que llega(ba), a veces, a inhibir los deseos de participación" (Lorenz 69). Por su parte Máximo Eseverri la desdeña por "su mirada piadosa y sentimental" (Eseverri 154). Mientras que Adrián Caetano ha señalado el efecto de "morbosidad" generado en los espectadores (60).

24 Uno de sus objetivos "era contribuir a la reorganización del movimiento estudiantil (secundario)” (Lorenz 6o). Sin embargo, a pesar de reconocerse como militante, Pablo Díaz "no lo manifestaba en esas charlas, porque veía caritas de I4 años, a los padres que los traían” y se inhibía frente a ello.

25 En I988, La noche de los lápices se estrenó en televisión con una audiencia calculada en los tres millones de personas en medio de un clima de tensión entre el estado y los militares alrededor de la generación de las leyes de impunidad (Lorenz 66). Además, la película se difundió en las escuelas de todo el país, "e incluso en algunas de Chile y Uruguay" (Raggio, "La noche" 53). También cada I6 de setiembre se genera una marcha anual que se realiza en distintos puntos del país. Y por último, desde el I6 de setiembre $1998 \mathrm{se}$ celebra el "Día de los Derechos del Estudiante Secundario" en Buenos Aires (Lorenz 62).

26 La película fue vista en el cine por 25.030 espectadores (Hancevich y Soler IOI).

27 La película comienza con la voz en off de "una radio que informa sobre la movilización de tropas militares, y tras ello, de los movimientos de la Bolsa" (Manzano I7I). Y luego muestra no sólo el robo de bienes inmuebles por parte de los grupos de tareas, sino también cómo la madre de María, desesperada 
por saber de su hija, le "vende" la casa a un torturador quien termina asesinándola. hacernos partícipes de nuestra catástrofe moral" ("La Náusea"). En el mismo tono, Claudia Acuña esgrime que la película "saldó una deuda" del cine argentino (en Eseverri 158). Y Máximo Eseverri destaca el "vínculo estético con el horror (y) la reposición, al menos parcial, de algo que se consideraba inexorablemente perdido" (169).

29 Marco Bechis estuvo detenido en el CCDTyE "El Atlético" por cuatro meses, y tras las gestiones de sus familiares fue enviado a Italia donde reside actualmente (Manzano 157).

30 Esta intervención organizada por HIJOS funcionó a la vez como campaña de publicidad y escrache político. La evocación del desaparecido y el CCDTyE interrumpía el espacio urbano, demostrando que la desaparición de esa historia era el resultado de las mismas políticas neoliberales que habían generado una situación de pobreza y exclusión en el país (Manzano 155).

${ }^{31}$ La canción Aurora proviene de una ópera homónima escrita en italiano encargada por el gobierno argentino y estrenada en 1908. Luego de ser traducida al español, un decreto de 1945 la transformó en "saludo a la bandera". Visto el 20 de junio de 2014 en http://www.taringa.net/posts/info/12007622/La-historia-de-la-Cancion-a-laBandera-Aurora.html.

32 Noriega ("La Náusea" 1), González ("Procedimiento" 170) y Eseverri (157) también hacen hincapié en esta escena.

33 Para Pilar Calveiro "el poder desaparecedor ... arraigaba profundamente en la sociedad desde el siglo XIX, favoreciendo la desaparición de lo disfuncional, de lo incomodo, de lo conflictivo" (Calveiro, "Poder" 13). Aunque históricamente "la desaparición como forma de represión política apareció después del golpe de 1966", la modalidad represiva de los CCDTyE se instauró en 1975 y el poder desaparecedor y concentracionario alcanzó su pleno funcionamiento con el golpe militar de 1976 (26-27).

34 En el cine, la película fue vista por 194.059 espectadores (Rocha 846).

35 "En 1997, Bruno Stagnaro y Adrián Caetano codirigieron Pizza, birra, faso, la película fundacional de la tendencia realista del nuevo cine argentino" (Schwarzböck 9).

36 La Mansión Seré era una casona aislada ubicada en los suburbios de Buenos Aires, lo cual repercutía en el régimen interno del CCDTyE que dependía de la idiosincrasia de los guardias más que de la "burocratización" como en Garage Olimpo.

37 Las discusiones militantes que aparecen en el libro de Tamburrini no son trasladadas a la película. 
38 Esta situación ominosa no está clarificada en la película, pero el dato no es menor en tanto la "inversión de roles" coincide con la judicialización de los militares en 2006.

39 La cristianización de las imágenes de tortura es un recurso que aparece también cuando "picanean" a Pablo en La noche de los lápices (Raggio, "La noche" 69).

OBRAS CITADAS

A M A 0, A N A. La imagen justa. Cine argentino y política (1980-2007). Buenos Aires: Colihue, 2009.

BECH IS, мAR C 0. "Entrevista realizada por Juan Carlos Rivas Fraile el 30/o6/200o". N.p. http://www.garageolimpo.it/new-go/stampago/prensabechisesp.html. Bernazza, C LAudia. "Ley 25.779 de Anulación de las leyes de 'Punto Final' y

'Obediencia Debida'. 2003-2013. Diez años del proyecto nacional: Las leyes que cambiaron la(s) historia(s)”. Memoria, Verdad y Justicia (Año 1 / 2003): 2-19. http://www.claudiabernazza.com.ar/2003_2013/pdf/2003.pdf.

CAETANo, A DR IÁ n. "Algo que no se ve. (Entrevista a Israel Adrián Caetano)”. Estudio crítico sobre Crónica de una fuga. Ed. Silvia Schwarzböck. Buenos Aires: Editorial Picnic, 2007. 73-94.

Calveiro, pilar. Poder y Desaparición. Buenos Aires: Colihue, 2001.

-. Política y/o violencia. Buenos Aires: Grupo Editorial Norma, 2005.

C O NA DE P. Nunca Más. Informe de la Comisión Nacional sobre la desaparición de personas. Buenos Aires: Eudeba, 2006.

Colectivo Situaciones. 19 y 20. Apuntes sobre el nuevo protagonismo social. Buenos Aires: De Mano en Mano, 2002.

CRENZEL, EM L L O. "Introducción. Memorias y representaciones de los desaparecidos en Argentina, 1983-2008”. Los desaparecidos en la Argentina. Ed. Emilio Crenzel. Buenos Aires: Editorial Biblios, 2010. 11-24.

Crónica de una fuga. Dir. Israel Adrián Caetano. Argentina. Prod. 2oth Century Fox de Argentina, INCAA, K\&S.

DRA Per, susana. Afterlives of Confinement. Pittsburgh: Pittsburgh UP, 2012.

ESEVERRI, MÁXIM o. "Lo sublime y lo bello en el cine argentino sobre la desaparición forzada de personas. De Un muro de silencio a Garage Olimpo".

Una década de Nuevo cine argentino (1995-2005). Ed. Ignacio Amatriain. Buenos Aires: Ciccus, 2009. 143-170.

Feitlo Witz, margarite. A Lexicon of Terror: Argentina and the Legacies of Torture. Oxford/New York: Oxford UP, 2011.

Garage Olimpo. Dir. Marco Bechis. Francia/Italia/Argentina. Prod. Rai

Cinemafiction, Classic, Tele+.1999. 
GON ZÁ LE Z, H ORACi o. "Problemas y desafíos". 19 y 20. Apuntes sobre el nuevo protagonismo social. Ed. Colectivo Situaciones. Buenos Aires: De mano en mano, 2002. 44-52.

—. "Garage Olimpo: Procedimiento, ironía, argentinidad”. Escritos en Carbonilla. Figuraciones, destinos, retratos. Ed. Horacio González. Buenos Aires: Colihue, 2006. 165-170.

han CeVich, malba y Soler, Lorena. "Sobre lo (im)posible de recordar. La representación de los desaparecidos en el cine (1995-2003)". Los desaparecidos en la Argentina. Ed. Emilio Crenzel. Buenos Aires: Biblios, 2010. 99-111.

KUSNETZOFF, JUAN CARLOS. "Renegación, desmentida, desaparición y percepticidio como técnicas psicopáticas de la salvación de la Patria (Una visión psicoanalítica del informe de la Conadep)". Argentina, psicoanálisis, represión política. Ed. Óscar Abudara. Buenos Aires: Kargieman, 1986. 147-192.

Jelin, eliza Beth. Los trabajos de la memoria. Madrid: Siglo XXI, 2002.

JELIN, ELIZABETH Y LONGONI, ANA. "Introducción". Escrituras, imágenesy escenarios ante la represión. Eds. Elizabeth Jelin y Ana Longoni. Madrid: Siglo XXI, 2005. XI-XII

La noche de los lápices. Dir. Héctor Olivera. Argentina. Prod. Aries Cinematográfica Argentina. 1986.

LVOVICH, DANIEL Y BISQUERT, JAQUELINA. La cambiante memoria de la dictadura: discursos públicos, movimientos sociales y legitimidad democrática. Buenos Aires: Biblioteca Nacional, 2008.

LORENZ, FE DE Ric o. Combates por la memoria. Huellas de la dictadura en la historia. Buenos Aires: Capital Intelectual, 2007.

ma nZ A n o, va LER IA. "Garage Olimpo o como proyectar el pasado sobre el presente (o viceversa)". El pasado que miramos. Memoria e imagen ante la historia reciente. Eds. Claudia Feld y Jessica Stites Mor. Buenos Aires: Paidos, 2009. 155180.

No R IE GA, G U S TA vo. "La Náusea". Revista El Amante (septiembre 1999). http://www.garageolimpo.it/new-go/stampago/nota13.htm

—. "Fragmento de Gustavo Noriega en el Amante no 167, abril de 2006". Estudio crítico sobre Crónica de una fuga. Ed. Silvia Schwarzböck. Buenos Aires: Editorial Picnic, 2009. 95-115.

oberti alejandra y pittaluga roberto. Memorias en Montaje. Buenos Aires: El cielo por asalto, 2006.

RAGGIO, SANDRA. "La noche de los lápices: del testimonio judicial al relato cinematográfico". El pasado que miramos. Memoria e imagen ante la historia reciente. Eds. Claudia Feld y Jessica Stites Mor. Buenos Aires: Paidos, 2009. 4576. 
—. "La construcción de un relato emblemático de la represión: La noche de los lápices". Los desaparecidos en la Argentina. Ed. Emilio Crenzel. Buenos Aires: Biblios, 20IO. I37-160.

RANCIÈRE, JACQUES. "Politics, Identification, Subjectivization". The Question of Identity. Ed. John Rajkman. New York: Routledge, 1995. 63-72.

rocha, Carolina. "Contemporary Argentine Cinema During Neoliberalism". Hispania 92.4 (2009): 84 $\mathrm{I}^{-8} 8 \mathrm{I}$.

ROZITCHNER, LEÓN. "La ruptura de la cadena del terror". 19 y 20. Apuntes sobre el nuevo protagonismo social. Ed. Colectivo Situaciones. Buenos Aires: De mano en mano, 2002. 44-46.

SCHWARZBö Cк, sylvia. Estudio crítico sobre Crónica de una fuga. Buenos Aires: Editorial Picnic, 2007.

TA Y L OR, DIANA. Disappearing Acts: Spectacles of Gender and Nationalism in Argentina's "Dirty War". Durham: Duke UP, 1997.

VEzZet TI, hu go. Sobre la violencia revolucionaria. Buenos Aires: Siglo XXI, 2009. 